\title{
An unusual cause of apparent epilepsy: ECG and EEG findings in a case of Jervell Lange-Neilson syndrome
}

\author{
P. J . S E L B Y A N D M V. D R I VER \\ From the University Department of Neurology and Departments of Clinical Neurophysiology, \\ Maudsley Hospital and King's College Hospital, London
}

SUMMARY A case is presented of apparent epilepsy which proved to be due to recurrent ventricular tachyarrhythmias (torsade de pointe). The relationship between the cardiac arrhythmia and changes in the electroencephalograph is recorded and analysed. This is probably an example of the 'Jervell Lange-Neilson' syndrome of cardiac arrhythmias which may produce ictal episodes, prolongation of the QTo interval of the ECG, and sensori-neural deafness. The features of the syndrome, its pathology and treatment, and its relevance to the management of epilepsy are discussed.

The differential diagnosis between cardiac and epileptic ictal episodes is a common clinical problem, and we present here a case of frequent epileptiform seizures which illustrates the difficulties. It brings to notice a little recognised cause of apparent epilepsy.

\section{Case report}

A 17 year old girl presented with a six week history of frequent epileptiform fits. She was observed to lose consciousness suddenly, extend her arms and legs maintaining tone, and turn her head to the right. These episodes lasted a few minutes only, and she recovered spontaneously, of ten crying. Lesser episodes with brief loss of consciousness but no motor features also occurred. She was frequently incontinent during the episodes. Attacks occurred 10 to 20 times in 24 hours including nocturnal episodes. Her past history was of a single unexplained episode of loss of consciousness 18 months earlier, congenitally dislocated hips and mild 'mental retardation' (IQ 74) noted from the age of 8 to 9 years. No definite cause had been found for the latter although it had been attributed to an unconfirmed anaesthetic accident occurring at 18 months. There was no relevant family history

Address for correspondence and reprint requests: Dr P. J. Selby, Clinical Research Fellow, Institute of Cancer Research (Block F), Clifton Avenue, Sutton, Surrey SM2 5PX, England.

Accepted 15 July 1977 and no parental consanguinity. The initial diagnosis was minor motor epilepsy but treatment with phenytoin, primidone, and sodium valproate had produced no definite improvement.

On examination at the Maudsley Hospital, she was small $(1.55 \mathrm{~m}$ and $45 \mathrm{~kg}$-within the $3 \mathrm{rd}$ percentile), with normal bodily proportions. Her pulse was irregular with frequent extrasystoles but cardiovascular and general examination was otherwise normal. Neurologically, she showed 'drusen' of the optic nerve head, moderately severe dysarthria, ataxia, and nystagmus, and mild pyramidal tract signs in the left leg with brisk tendon jerks and an extensor plantar response. Her left foot was slightly smaller than the right.

Routine investigations for the cause of epilepsy and mental retardation were all normal. Anticonvulsant blood levels on admission were $3 \mathrm{mg} / 1$ of phenytoin, $9 \mathrm{mg} / 1$ of primidone, and $4 \mathrm{mg} / 1$ of phenobarbitone, all well below established toxic levels. An ECG taken to investigate the irregular pulse confirmed frequent ventricular extrasystoles, often ' $R$ on $T$ ', but during an incidental seizure a ventricular tachyarrhythmia identified as torsade de pointe (Krikler and Curry, 1976) was seen. A 24 hour continuous electromagnetic tape recording of the ECG showed frequent runs of torsade correlating with the clinical ictal episodes (Fig. 1). All known causes of acquired torsade de pointe were excluded (Krikler and Curry, 1976). The $\mathrm{QT}_{\mathrm{c}}$ measurement of her ECG was $0.45 \mathrm{~s}$ (upper 1102 


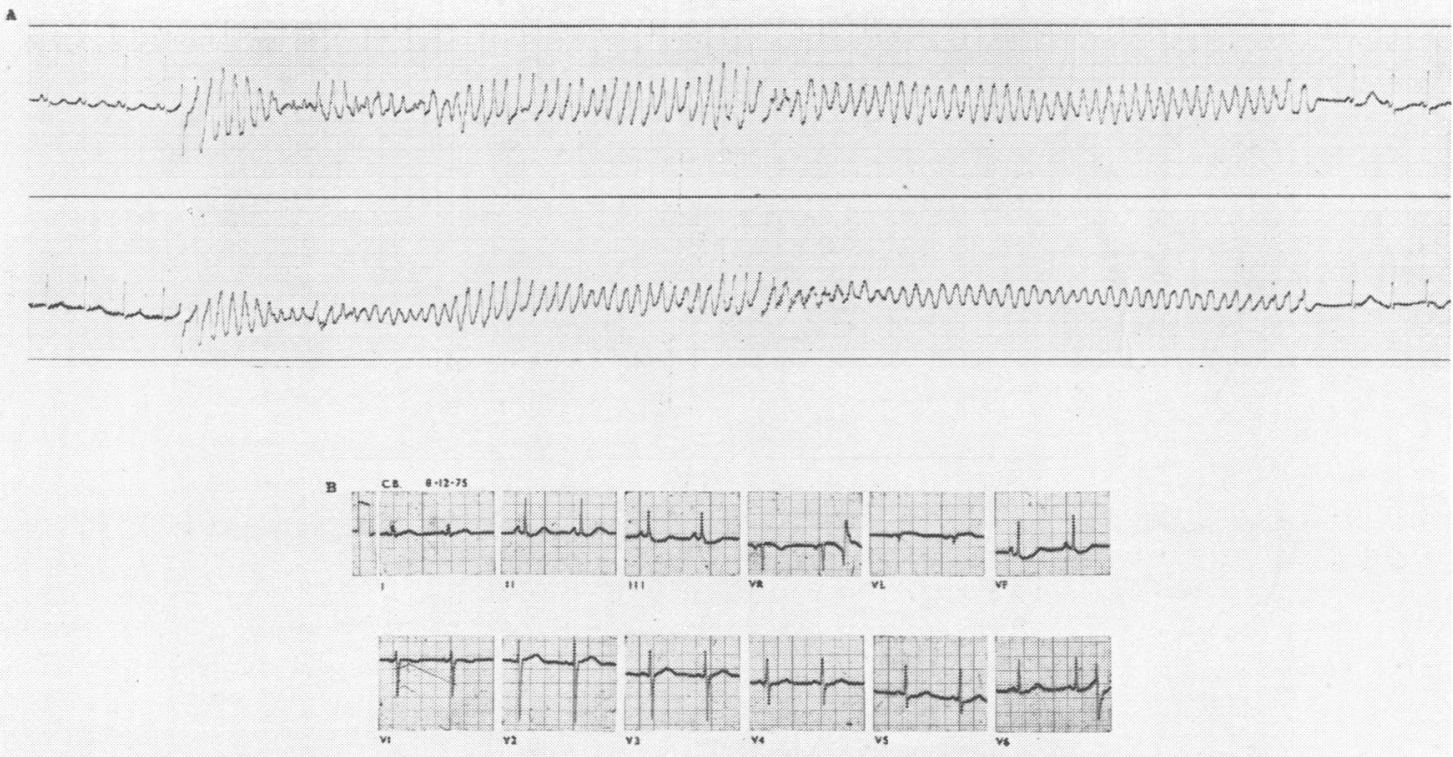

Fig. 1 Torsade de pointe as recorded on a 24-hour electromagnetic tape recording with an example of the 12 lead ECG.

limit of normal $0.425 \mathrm{~s}$ ) but the 12 lead ECG was otherwise normal. The cardiac electrophysiological studies that were performed will be described elsewhere (Selby et al., 1977).

The EEG was recorded on two occasions before the possible significance of a cardiac disorder was recognised. The first showed prominent bilateral slow wave phenomena during several typical attacks which suggested that these could be epileptic in nature. The second, during which no attack occurred, showed some normal alpha rhythm and large amounts of mixed frequency slower activity, particularly on the right side. No spikes or complex wave forms were present and there was no unusual photosensitivity. The third EEG included the ECG in one channel (Figs. 2, 3, and 4) and three typical attacks occurred, each related to a period of prolonged ventricular tachycardia (1034 s) and associated with bilateral slow waves in the EEG. One less prolonged tachycardia $(8 \mathrm{~s})$ was associated with slow EEG waves and some body movements but no definite attack was noted. Seven periods of tachycardia (duration 0.8-5.2 s) were accompanied by neither attack nor EEG slow waves (Table). On each of the four occasions when patient movement artefacts and EEG slow waves appeared, all had a similar latency (4-6 s) from the onset of the tachycardia, but the slow waves invariably ended before the movement arte- facts. The exact relationship in time between clinical features of the attack and EEG/ECG changes is not clearly established.

An audiogram showed a mild bilateral high tone sensory hearing loss, and an EMI scan showed enlargement of the lateral and third ventricles.

Anticonvulsants were withdrawn and she was treated with mexilitine, a new Class I antiarrhythmic drug (Singh and Vaughan-Williams, 1972) which succeeded in abolishing all her attacks and, in high doses, in suppressing the recorded arrhythmias. At the time of writing she has remained well and attack free for 12 months on mexilitine and later on propranolol in addition. Details of the treatment regime, electrophysiological response to mexilitine and drug levels will be reported by Selby et al. (1977). ECGs recorded in her parents and sibling were normal.

\section{Discussion}

\section{NATURE OF THE ATTACKS}

Interictal EEGs in patients with epilepsy may not show spikes, spikewave, or other phenomena of clear epileptic significance, and records taken during some seizures-for example, psychomotor -may show bilateral slow waves. In these respects the first two EEGs would not be regarded as out- 


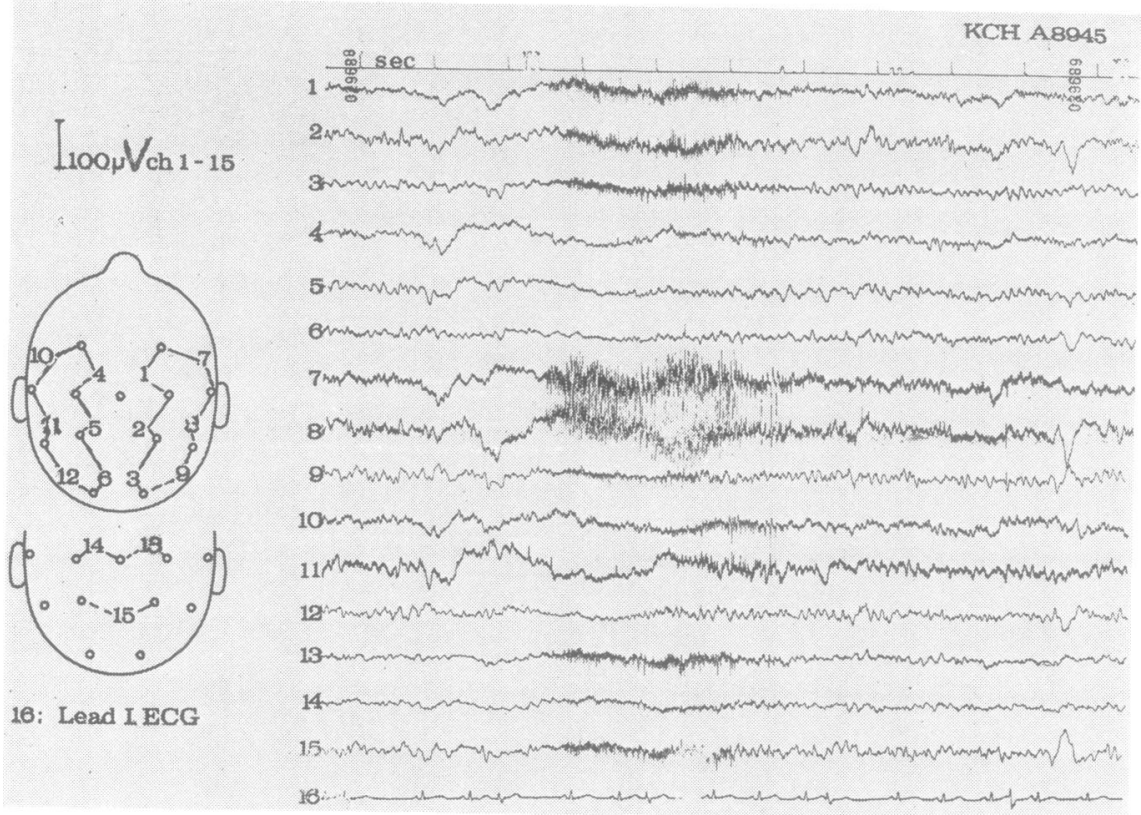

Fig. 2 Bipolar scalp EEG channels 1-15; lead 1 ECG in channel 16. Several channels, especially 4,7,8,10, and 11, show movement artefacts, and others, especially 7 and 8 , muscle artefacts such as occurred apparently at random throughout the recording. Some normal alpha rhythm is present bilaterally but mixed with slower waves. One high voltage right posterior temporal-occipital wave appears near the end of this excerpt (channels 2, 8, 9, 15).

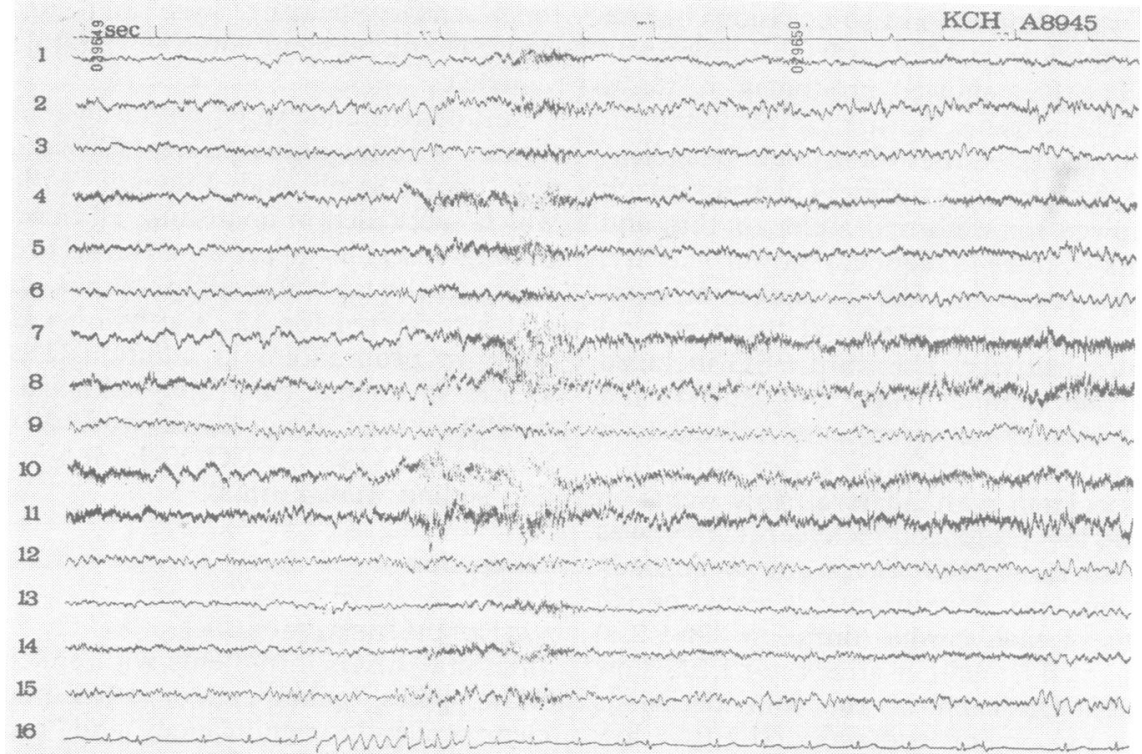

Fig. 3 Electrode pattern as Fig. 2. A 2.2 seconds period of ventricular tachycardia (channel 16) is not associated with abnormal EEG change. 


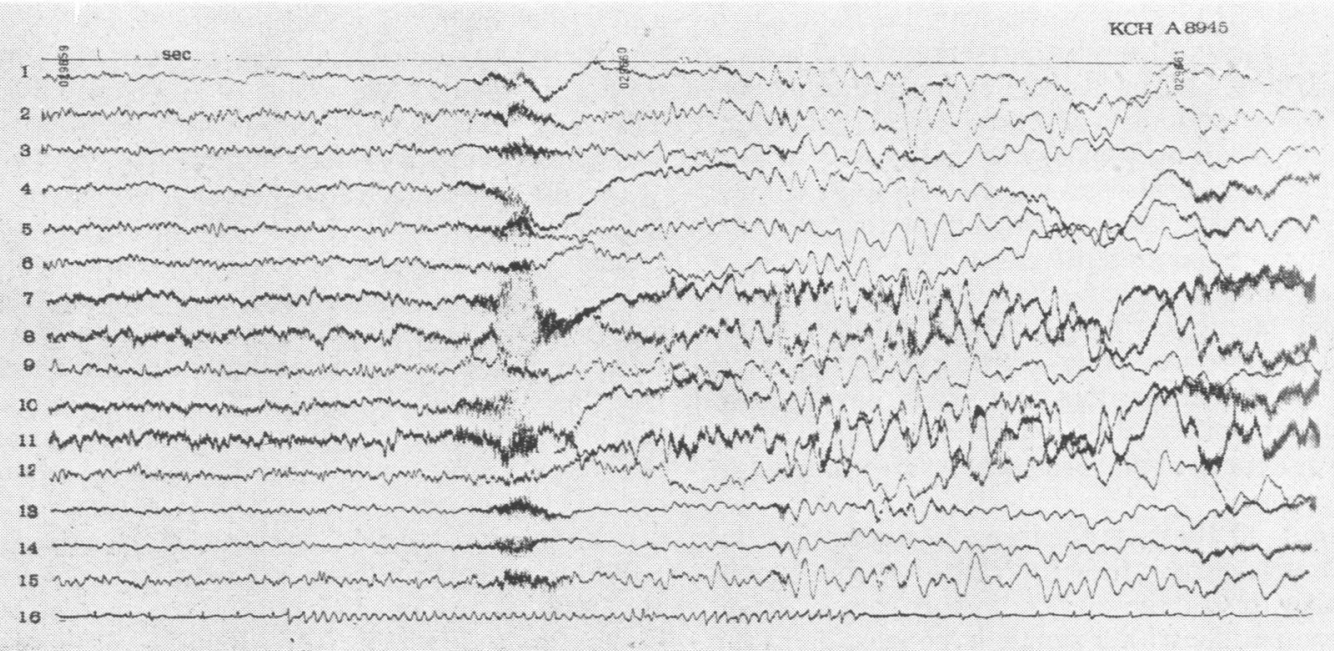

Fig. 4 Electrode pattern as Fig. 2. A 10 seconds period of ventricular tachycardia is associated with patient movements (very slow baseline drift) and rhythmic bilateral slow EEG waves. Both are well developed some six seconds from the start of the tachycardia and continue after it ends.

Table Duration of tachycardia and associated phenomena

\begin{tabular}{|c|c|c|c|c|c|c|}
\hline $\begin{array}{l}\text { Duration of } \\
\text { tachycardia } \\
\text { (seconds) }\end{array}$ & $\begin{array}{l}\text { Appearance of } \\
\text { bilateral slow } \\
\text { waves }\end{array}$ & $\begin{array}{l}\text { Latency of } \\
\text { slow waves } \\
\text { (seconds) }\end{array}$ & Clinical 'attack' & $\begin{array}{l}\text { Slow wave } \\
\text { duration after } \\
\text { end of tachycardia } \\
\text { (seconds) }\end{array}$ & $\begin{array}{l}\text { Movements } \\
\text { latency from } \\
\text { start of tachycardia } \\
\text { (seconds) }\end{array}$ & $\begin{array}{l}\text { Duration of } \\
\text { movements } \\
\text { (seconds) }\end{array}$ \\
\hline 1 & No & & No & & & \\
\hline 13 & Yes & 5 & Yes & 10 & 5 & 65 \\
\hline 8 & Yes & 6 & No & 2 & 6 & 10 \\
\hline 0.8 & No & & No & & & \\
\hline 2.2 & No & & No & & & \\
\hline 10 & Yes & 6 & Yes & 8 & 6 & 26 \\
\hline 3.2 & No & & No & & & \\
\hline 0.8 & No & & No & & & \\
\hline 5.2 & No & & No & & & \\
\hline 1.1 & No & & No & & & \\
\hline 34 & Yes & 6 & Yes & 10 & 4 & 70 \\
\hline
\end{tabular}

side the range encountered in 'true' epilepsy. Mental handicap may be associated with abnormally slow and asymmetrical EEG activity as seen in the second record. Patients with gross congenital cardiac disease not uncommonly show similar features. The periods of acute cardiac dysfunction could, perhaps, precipitate true epileptic fits in a susceptible subject either directly (for example, through a vago-medullary reticular pathway), or indirectly (for example, through emotional stress or cerebral hypoxia from reduced blood flow). Alternatively, the attacks could be not truly epileptic but rather periods of confused behaviour with or without loss of consciousness induced by cerebral hypoxia.

It is not possible to determine unequivocally from any of the EEG recordings which, if any, of these mechanisms was responsible, but there are definite strong points in favour of the last. The third EEG shows that a minimum of 4-6 seconds of tachycardia was a prerequisite both of the clinical attack and the bilateral very slow EEG activity, and also that whatever the actual duration of the tachycardia, provided an attack occurred, the cerebral dysfunction responsible for the slow waves came to an end within 8-10 seconds of the cessation of the tachycardia. The close time relationship between the onset of the ECG and EEG phenomena is most likely to be due to an acute fall in cardiac output with resulting cerebral hypoxia, and the time for EEG recovery to follow re-establishment of the cerebral blood flow. 
Bilateral EEG slow waves can be induced in healthy subjects through their breathing low oxygen mixtures, and in healthy children and adolescents by strenuous voluntary hyperventilation, when the resulting hypocapnia is thought to produce reflex cerebral vasoconstriction and hypoxia. EEG slow waves of a similar character may also be induced by unilateral carotid compression in patients with cerebrovascular disease, in which case the latency is 6-8 s. The 'off' effect after carotid compression may not be clearly apparent, but where the internal carotid artery has been explored surgically, ligature induced EEG slow waves disappear about 5-6 seconds after release of the ligature.

Timing of these procedures is necessarily inexact but, even so, they indicate that the various EEG features of the attacks in this patient are at least compatible with a simple hypoxic rather than an epileptic basis.

\section{NATURE OF THE DISEASE}

The association of attacks due to cardiac arrhythmias, prolongation of the QT interval on the ECG and sensory hearing loss, link this case to the socalled surdo-cardiac syndrome of Jervell and Lange-Neilson (1957). They described a family of four siblings in whom syncope and sudden death were associated with congenital deaf mutism and QT prolongation. Later, Romano et al. (1963) and Ward (1964) described a similar syndrome without hearing abnormalities. There are now over 200 cases, mainly in the cardiac literature (listed by Schwartz et al., 1976). This is predominantly a disease of children, and only some $10 \%$ of cases had their first attack after 10 years of age, although cases in the fourth and fifth decades are reported. The prognosis is mixed but sudden death in childhood is common, and survival to adult life is unusual.

The clinical features of the ictal episodes vary remarkably (Fraser et al., 1964; Singer et al., 1974). Minor episodes with chest or abdominal discomfort but no loss of consciousness occur as do major episodes with syncope and convulsions. Convulsions may mimic grand mal or focal epilepsy (Singer et al., 1974). Our experience that it may be clinically impossible to distinguish these attacks from true epilepsy is supported by the great frequency with which this was the initial firm diagnosis made in other described cases. There is little evidence to help distinguish hypoxic episodes from precipitated cerebral seizures in other described cases, and we are unaware of previous observations of the relationship between ECG changes and EEG changes. Optic 'drusen' are not a described association and the presence of neurological signs is unusual. When present, they have been explained as the result of hypoxic damage. This may be so in our case and this is compatible with the findings on EMI CAT scan.

The ECG usually shows a prolongation of the QTo measurement which may be minimal as in the present case. Inversion of the $\mathrm{T}$ wave at rest or on exercise, and extrasystoles are also common. Early authors suspected that the syncopes and convulsions were due to cardiac arrhythmias and this has now been amply confirmed. The terminology of the arrhythmias is confused and both ventricular tachycardia and ventricular fibrillation are described. In our case, and certainly in some of the other variously labelled cases, the term torsade de pointe is appropriate. This is a ventricular tachyarrhythmia in which the QRS axis of the ECG fluctuates and which is frequently self-limiting. The nature and causes of this arrhythmia are reviewed by Brochier et al. (1972) and Krikler and Curry (1976).

The genetics and pathology of the syndrome are uncertain but considerable information is available. Sporadic cases occur but several authors report a clear autosomal dominant pattern for the syndrome without deafness (Gale et al., 1970; Chaudron et al., 1976), while some propose a recessive pattern (Fraser et al., 1964). Mathews et al. (1972) reported a family in which the disorder occurred with and without deafness, the latter being inherited separately in a dominant fashion. Pathological studies are few (Fraser et al., 1964; James, 1967) and no consistent abnormality is found. James (1967) found abnormal sinus node arteries similar to those described by him in Dalmatian dogs who suffer from deafness and sudden death. Friedmann et al. (1968) found absence of the organ of Corti and other degenerative changes in the middle ear. Lack of balanced sympathetic drive to the heart is a favoured hypothesis for the pathogenesis of the QT prolongation (Schwartz et al., 1976) and is supported by the observations that (1) propranolol is beneficial; (2) arrhythmias are often triggered by emotion or exertion; (3) experimental stimulation of the left stellate ganglion or ablation of the right stellate ganglion in dogs prolongs the QT interval (Yanowitz et al., 1966); and (4) left stellate ganglionectomy may be beneficial (Moss and McDonald, 1971; Schwartz et al., 1976).

Treatment for this syndrome is still not universally agreed but it is clear that propranolol is of benefit (Schwartz et al., 1976) and in our case mexilitine proved highly effective. Quinidine and procainamide are probably contraindicated because of their action to prolong the QT interval. 
Phenytoin (Ratshin et al., 1971; Mathews et al., 1972), bretylium tosylate (Singer et al., 1974), digoxin (Chaudron et al., 1976), lignocaine, potassium, and diazepam have all been tried with variable but limited success.

\section{DIAGNOSIS AND RELEVANCE OF THE DISEASE}

It would seem important that this disease be considered in the differential diagnosis of seizures and syncope in children and adults. The resting EEG is usually normal and never frankly epileptic, and the presence of extrasystoles may be suggestive of this diagnosis, although they are not invariable and are present in $1 \%$ of the normal population. The diagnosis may be made by accurate measurement of the QT interval corrected for rate $\left(\mathrm{QT}_{0}\right)$, although a few cases are reported in which QT prolongation was only apparent on exercise (Von Bernuth et al., 1973). Other possible pitfalls are that the QT interval is decreased by increasing age and by large doses of phenytoin. QT prolongation in the ECG of an apparent epileptic does not confirm this diagnosis because it may result from many causes, commonly phenothiazines and tricyclic antidepressants (Singer et al., 1974). The most reliable method for confirming the diagnosis is the 24 hour electromagnetic ECG tape recording, although even then the possibility that ventricular arrhythmias may result from epileptic fits should be borne in mind (White et al., 1961).

This condition may be relevant to the not uncommon problem of sudden unexplained death in young epileptics. Hirsch and Martin (1971) studied 19 such cases in some detail and observed that one of them was known to have QT interval prolongation.

It is suggested that this condition be considered in the differential diagnosis of all idiopathic epilepsies and of any unexplained ictal episode. Atypical seizures, a normal EEG and extrasystoles may all be clues but it can only be reliably diagnosed by ECG recording and measurement of the QTo at rest and perhaps on exercise. It represents a potentially fatal and eminently treatable cause of apparent epilepsy.

The cardiac investigations and therapy, which are published elsewhere, were performed by Dr David Jewitt, Consultant Cardiologist, King's College Hospital, and Dr Michael McComish, Research Fellow, King's College Hospital. We would like to thank Professor David Marsden for permission to describe his patient, for advice throughout the study, and for reading the manuscript. Many thanks are due to Mrs Jenny Mudditt who typed the script.

\section{References}

Brochier, M., Motte, G., and Fauchier, J. P. (1972). Tachycardie ventriculaire en torsades de pointe. Actualités Cardio-vasculaires Médico-chirurgicales, 6, 171-194.

Chaudron, J. M., Heller, F., Van den Berghe, H. B., and Le Bacq, E. G. (1976). Attacks of ventricular fibrillation and unconsciousness in a patient with prolonged QT interval. A family study. American Heart Journal, 91, 783-791.

Fraser, G. R., Froggatt, P., and James, T. N. (1964). Congenital deafness associated with electrocardiographic abnormalities, fainting attacks and sudden death. Quarterly Journal of Medicine, 33, 361-385.

Friedmann, I., Fraser, G., and Froggatt, P. (1968). Pathology of the ear in the cardio-auditory syndrome of Jervell and Lange-Neilson. Journal of Laryngology and Otology, 82, 883-896.

Gale, G. E., Bosman, C. K., Tucker, R. B., and Barlow, J. B. (1970). Hereditary prolongation of the QT interval-study of two families. British Heart Journal, 32, 505-509.

Hirsch, C. S., and Martin, D. L. (1971). Unexpected deaths in young epileptics. Neurology (Minneapolis), 21, 682-690.

James, T. N. (1967). Congenital deafness and cardiac arrhythmias. American Journal of Cardiology, 19, 627-643.

Jervell, A., and Lange-Neilson, F. (1957). Congenital deaf mutism, functional heart disease with prolongation of the QT interval and sudden cleath. American Heart Journal, 54, 59-68.

Krikler, D. M., and Curry, P. V. L. (1976). Torsade de pointe, an atypical ventricular tachycardia. British Heart Journal, 38, 117-120.

Mathews, E. C., Blount, A. W., and Townsend, J. I. (1972). QT prolongation and ventricular arrhythmias with and without deafness in the same family. American Journal of Cardiology, 29, 702-711.

Moss, A. J., and McDonald, J. (1971). Unilateral cervico-thoracic sympathetic ganglionectomy for the treatment of long QT interval syndrome. New England Journal of Medicine, 285, 903-904.

Ratshin, R. A., Hunt, D., Russell, R. O., and Rackley, C. E. (1971). QT interval prolongation, paroxysmal ventricular arrhythmias and convulsive syncope. Annals of Internal Medicine, 75, 919-924.

Romano, C., Gemme, G., and Pongiglione, R. (1963). Aritmie cardiache rare dell'eta pediatrica. Clinical Pediatrics, 45, 656-683.

Schwartz, P. J., Periti, M., and Malliana, A. (1976). The long QT syndrome. American Heart Journal, 89, 378-389.

Selby, P. J., McComish, M., and Jewitt, D. E. (1977). Submitted for publication.

Singer, P. A., Crampton, R. S., and Bass, N. H. (1974). Familial QT prolongation syndrome. Archives of Neurology (Chicago), 31, 64-66.

Singh, B. N., and Vaughan-Williams, E. M. (1972). Investigation of the mode of action of a new anti- 
dysrhythmic drug. British Journal of Pharmacology, 44, $1-9$.

Von Bernuth, G., Belz, C. G., Evertz, W., and Stauch, M. (1973). QTU-abnormalities, sinus bradycardia and Adams Stokes attacks due to ventricular tachyarrhythmia. Acta Pediatrica Scandinavica, 62, 675679.

Ward, O. C. (1964). New familial cardiac syndrome in children. Journal of the Irish Medical Association, 54, 103-106.
White, P. T., Grant, P., Mosier, J., and Craig, A. (1961). Changes in cerebral dynamics associated with seizures. Neurology (Minneapolis), 11, 354-361.

Yanowitz, F., Preston, J. B., and Abildskor, J. A. (1966). Functional distribution of right and left stellate innervation to the ventricles. Circulation Research, 18, 416-438. 